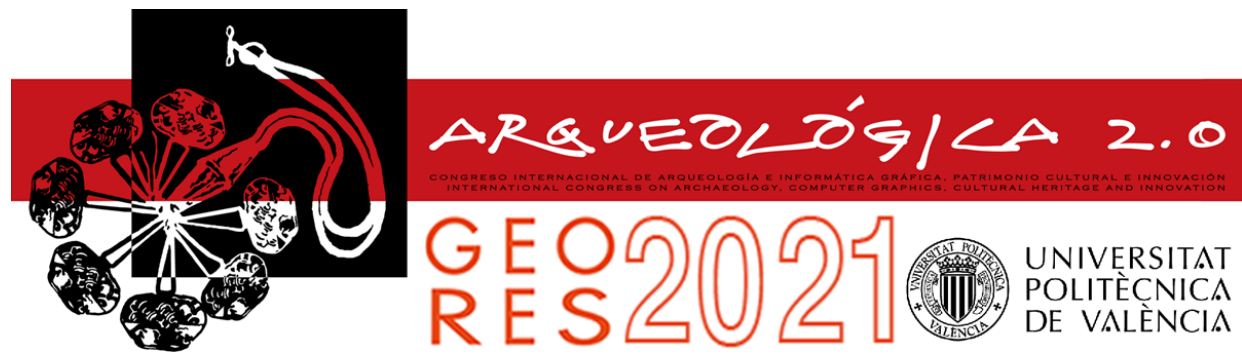

Proceedings of the joint international event $9^{\text {th }}$ ARQUEOLÓGICA

$2.0 \& 3^{\text {rd }}$ GEORES

Valencia (Spain).

26-28 April 2021

\title{
ACCESSIBILITY TO UNDERWATER CULTURAL HERITAGE: THE INTERACTIVE WEB NAVIGATION OF THE ROMAN SUBMERSED VESSEL OF CALA MINNOLA
}

\author{
Andrea Scianna a, ${ }^{a}$, Giuseppe Fulvio Gaglio ${ }^{a}$, Marcello La Guardiab \\ a ICAR-CNR (High Performance Computing and Networking Institute - National Research Council of Italy) at GISLab, via Ugo La Malfa \\ 153, 90146 Palermo, Italy. andrea.scianna@icar.cnr.it; gfulvio.gaglio@gmail.com \\ ${ }^{\mathrm{b}}$ Department of Engineering, Polytechnic School of University of Palermo, Viale delle Scienze, Edificio 10, 90128 Palermo, Italy. \\ marcellolaguardia87@libero.it
}

\begin{abstract}
:
The possibilities offered by photogrammetric reconstruction based on computer vision algorithms allowed in recent years to develop new interesting solutions for the spread and dissemination of knowledge on Cultural Heritage $(\mathrm{CH})$. In the same way, the recent technological development in the field of Virtual Reality (VR) has offered new possibilities for the creation of interactive virtual environments, which can be freely accessed via the browser using any type of device. These technologies acquire an additional relevance if applied to archaeological sites or monuments that are difficult to access, or even totally inaccessible, except by specialized personnel. In this case, the virtual fruition on the web becomes strategic for the valorization of $\mathrm{CH}$, as in the case of submerged archaeological sites, where the virtual tour represents in fact the only opportunity of diffuse accessibility. The present case shows the virtual reconstruction of the wreck area of the Roman ship found on the seabed of Cala Minnola on the island of Levanzo (TP, Italy). The model, obtained from a Structure from Motion (SfM) processing of a chunk of photos originally intended for a traditional photogrammetric survey, was edited and inserted into a specific template based on HTML5 and linked to Javascript libraries (Three.js) which allowed browsing on the web. Subsequently, the navigation model was suitability adapted to the purpose, in order to make the online virtualnavigation as intuitive as possible, considering the navigation with any type of device and using the most common browsers (Chrome, Safari, Firefox). This experimentation is a viable procedure for spreading the knowledge of a submerged archaeological site in a simple way, by web-browsing. This type of navigation models with the future development of $5 \mathrm{G}$ networks will find greater diffusion and application, with the possibility of including increasingly complex environments in the navigation.
\end{abstract}

Keywords: Survey, Cultural Heritage, 3D modelling, photogrammetry, WebGL, Virtual Reality

\section{Introduction}

The work reported in this article shows the potential and importance of online virtual fruition of inaccessible archaeological sites, in a period in which the enhancement of cultural heritage is particularly connected with the spread of knowledge regarding cultural goods (loannides et al., 2017). Advances in information technologies, applied in particular to survey and photogrammetric reconstruction techniques, now allow very realistic virtual reconstructions of real objects and environments (Banfi, 2020; Barrile, Fotia, Bilotta \& De Carlo, 2019; Scianna, Gaglio \& La Guardia, 2020; Masiero et al., 2019).

The importance of virtual visualization is now undisputed, as it allows visitors to observe, and, therefore, study objects of artistic and cultural value from new points of view. Moreover, thanks to it, it is possible to reach a much larger number of users, both for the entertainment character that distinguishes it, and because it allows access to visual and sensory information that is otherwise unreachable. The problem of accessibility to $\mathrm{CH}$, in fact, does not concern only those people with physical disabilities. In this regard, some archaeological sites, in fact, represent proper features that are not compliant with the accessibility to visitors, such as the presence of very fragile elements or parts that risk being easily altered. Furthermore, many sites are unreachable for most people, as they are located in particular, remote places, inside private property or because the paths to reach them make access to places too complicated (Dominici, Alicandro \& Massimi, 2017; Scianna \& La Guardia, 2019). This is the case, in particular, of submerged archaeological sites, which can only be reached in particular conditions and only by specialized personnel, and represents a challenging field for photogrammetric reconstructions (Skarlatos, Menna, Nocerino \& Agrafiotis, 
2019; Vlachos, Berger, Mathelier, Agrafiotis \& Skarlatos, 2019; Balletti, Beltrame, Costa, Guerra \& Vernier, 2015; Pacheco-Ruiz, Adams \& Pedrotti, 2018).

Therefore, the virtual model, in this case, represents a valid tool for the dissemination of knowledge (Skarlatos \& Agrafiotis, 2020; Liarokapis et al., 2017), as it is able to make users interact with three-dimensional contexts that represent real environments in other way not accessible. In this context, the aspect of sharing information on the network is a factor that today is becoming increasingly important due to the widespread use of mobile devices such as smartphones and tablets and the improvement of network connections. In our case, the possibilities offered by the WebGL JavaScript libraries, based on HTML5, allow showing three-dimensional contents in real-time and without the need to download client-side applications, making the sharing of cultural heritage easier and more immediate (Campanaro, Landeschi, Dell'Unto \& Touati, 2016; Scianna, La Guardia \& Scaduto, 2016; Mortara et al., 2014).

In the following sections of this article, a review of the advances in ITC technologies for $\mathrm{CH}$ will be initially shown, with particular reference to three-dimensional reconstructions and VR. Subsequently, the case study here presented, regards the reconstruction and dissemination on the network, with WebGL libraries, of the three-dimensional model of the underwater archaeological site of Cala Minnola, in Levanzo (TP, Italy). This model has been obtained from the photogrammetric reconstruction of a set of underwater images belonging to the Superintendence of the Sea of the Sicilian Region, originally intended for a traditional photogrammetric survey.

\section{Recent technological advances for $\mathrm{CH}$ sites (state of art)}

The use of virtual reality is now widespread in various fields, and in recent years, it has affected the world of Cultural Heritage. The digitization of Cultural Heritage is the basis of the new way of transmitting knowledge brought forward by new media technology (Bekele, Pierdicca, Frontoni, Malinverni \& Gain, 2018; Brovelli, Hogan, Minghini, \& Zamboni, 2013). This primary operation makes it possible to return information in different forms and for different purposes, satisfying the requirements of speed and immediacy and improving its usability. Applied to Cultural Heritage, Virtual Reality has in fact proved to be an interesting means for the reconstruction, preservation and safeguarding of works belonging to the past which have now been destroyed by time. The Digital Michelangelo project is an excellent example of the possibilities offered by this technique (Levoy et al., 2000). Great advantages have also been obtained in the digital reconstruction of damaged parts (Magnenat-Thalmann \& Papagiannakis, 2005) or in the support of restoration interventions, as in the case of Bamyan's Buddah (Grün, Remondino \& Zhang, 2004). Furthermore, the three-dimensionality and virtualization are capable of exploiting the emotions that images can arouse in the observer (Meschini, 2011). The immediate degree of understanding of images compared to language-based mediation alone has made these applications also very effective in the field of dissemination and cultural education (Carrozzino \& Bergamasco, 2010).
Archaeological sites, museums and art collections have long begun to rely on these technologies also to increase the involvement of the viewer and to offer more complete knowledge of what is observed. Interactive monitors, 3D printing, mobile applications, consoles with threedimensional reconstructions and augmented reality, therefore, aim to increase interest in culture in an innovative way (Ballarin, Balletti \& Vernier; 2018; Fernández-Palacios, Morabito \& Remondino, 2017; Becattini et al., 2016). These technologies have also allowed exhibiting objects from collections that cannot normally be shown due to fragility or limited space available. Making use of virtuality, therefore, offers the possibility of interacting with objects in the collection even at a distance, thus involving a greater number of users, including disabled people and students (Scianna \& Di Filippo, 2019; Walczak, Cellary \& White, 2006). The virtual movement to other places for temporary exhibitions is also possible, as in the case of the exhibition of the Vietnamese Treasury in Germany in 2016 (Kersten, 2018).

However, special equipment and space dedicated to them are often required, as in the case of the CINECA Virtual Theater (Farella, Brunelli, Benini, Ricco \& Bonfigli, 2005). VR applied to $\mathrm{CH}$ offers two possibilities of Virtual Museum reconstruction. In fact, it is possible to produce both virtual reconstructions of existing museums, including all the objects in the collection, and reconstructions of places that no longer exist, strongly deteriorated or difficult to access to allow the public to use them easily (Lepouras \& Vassilakis, 2005). The latter case is of particular importance precisely because of the precious possibility to share visual information of places that cannot be any longer visited in reality. In particular, virtuality has proved very useful in the reconstruction of submerged archaeological sites, considering their strong limitations of real accessibility. The remains from the ancient marine trade, a great testimony to the cultural exchange of peoples in the Mediterranean, are in fact unreachable by the vast majority of the public and the possibility of disseminating their knowledge on a large scale has always interested researchers in the sector. In this field, photogrammetric reconstruction techniques have been applied to nautical archaeology since the 1960s, when photography was used in submerged sites as a recording, documentation and cataloguing tool. The first photogrammetric surveys used a manual process of measuring and observing images in order to recreate models (Bass, 1966).

The development of computer science subsequently made it possible to speed up and automate most of the reconstruction operations. In this way, underwater photogrammetry has become both more powerful and accessible, as demonstrated by the reconstruction of the remains of Dolia in the Meloria Shoals (Canciani, Gambogi, Romano, Cannata \& Drap, 2003). To date, current software, using algorithms based on Structure from Motion (SfM), allow the three-dimensional automatic reconstruction of the detected environments, limiting the effect of the refraction of the sea and calculating the relative position of the cameras. Underwater photogrammetry, therefore, presents itself as a powerful tool capable of supporting archaeology, avoiding significant invasive strategies that could alter a site characterized by cultural relevance. Hence, this technology, in the context of the study of submerged 
historical finds, allows acquiring geometrical information necessary to share a relevant part of the Cultural Heritage not accessible for the majority of users (Menna, Agrafiotis, \& Georgopoulos, 2018; Yamafune, Torres \& Castro, 2017). The wreck of Cala Minnola, a case study presented in this article, was also the subject of experimentation within the VISAS project, dedicated to the enhancement and virtual use of underwater archaeological sites (Bruno et al., 2017). In fact, an application was created that allows you to navigate within a virtual environment, reproducing in detail the real conditions of the site. Navigation involves the use of 3D monitors, related glasses and a multi-touch tablet for movement. In this case, therefore, necessary to make use of special tools and to install the necessary required software.

Otherwise, the recent possibility of sharing virtual representations also on the web has offered the opportunity to create several applications, where it is possible to navigate within increasingly engaging 3D environments, using devices that are easily accessible to the majority of the public.

In fact, it is possible to follow pre-established routes inside a touristic path, or to customize the virtual visit by choosing individual preferences. The ARCO project allows, for example, managing virtual exhibitions with the contribution of Augmented Reality (AR) technology (White et al., 2004). Remote archaeological sites, excavation activities or lost collections can thus be explored easily by users, offering them a deep knowledge of the cultural goods (Bruno et al., 2010). Dissemination via a web browser represents a tool for broad information sharing in a period of great diffusion of portable devices. It is now increasingly simple and natural to access information on the web through portable devices like smartphones and tablets than through PCs, used almost only for longer and more complex operations. In particular, today, through the development of WebGL, specific JavaScript libraries based on HTML5 models, it is possible to develop effective solutions for the creation of virtual three-dimensional environments freely real-time navigable on the web in an interactive way (Scianna, La Guardia \& Scaduto, 2016). Solutions particularly followed in the development of video games, such as the firstperson interactive navigation of online virtual environments, have proved to be very effective in involving the user in the exploration of a cultural site (Scianna \& La Guardia, 2018). The use of these technologies results to be smart, because allows users to easily discover virtual 3D environments on the web without the need to install applications on the client-side.

These considerations led to the development of the model described in the following paragraphs. Through advanced photogrammetric reconstruction techniques, 3D modelling and web development, the online interactive virtual reconstruction of the underwater archaeological site of Cala Minnola was developed, making a part of Italian cultural heritage currently accessible only to specialized personnel perfectly navigable and virtually explorable in the first person.

\section{The experimentation}

The creation of the virtual navigation model of the submerged archaeological site located close to Cala
Minnola, in the Sicilian island of Levanzo, follows a complex procedure (Fig. 1), starting from the acquisition of historical documentation and ending with the porting of the virtual navigation model on different kind of devices.

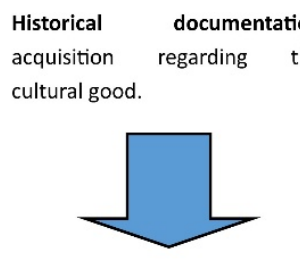

Survey operations based on images and Ground Control Points acquisition

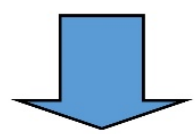

Digital Photogrammetric Reconstruction based on $\mathrm{SFM}$ algorithms

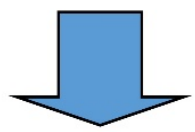

WebGL implementation of the 3D model inside a virtual environment, using proper lavascript strings inside the. $\mathrm{html}$ webpage.
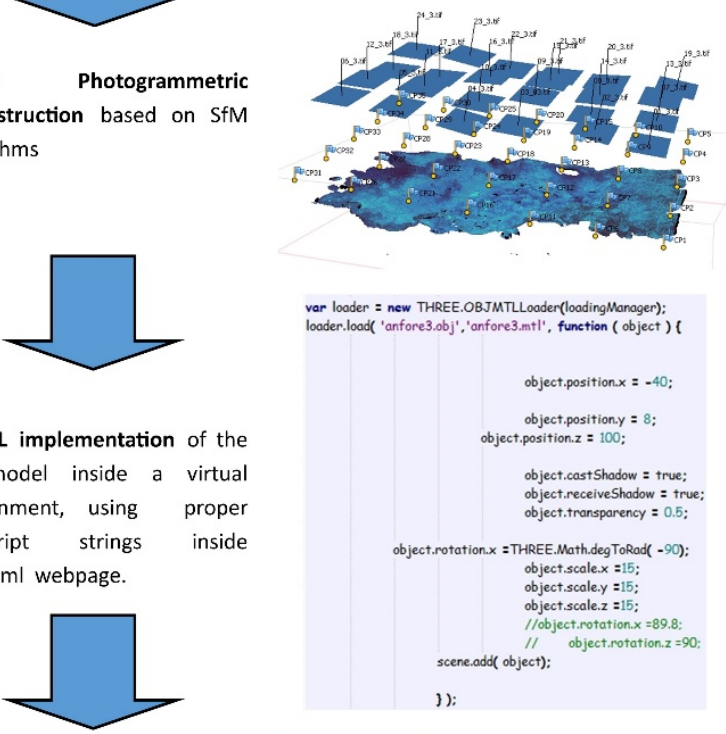

Oprtimization of the 3D environment navigation model, testing the web-browsing on different kind of devices.
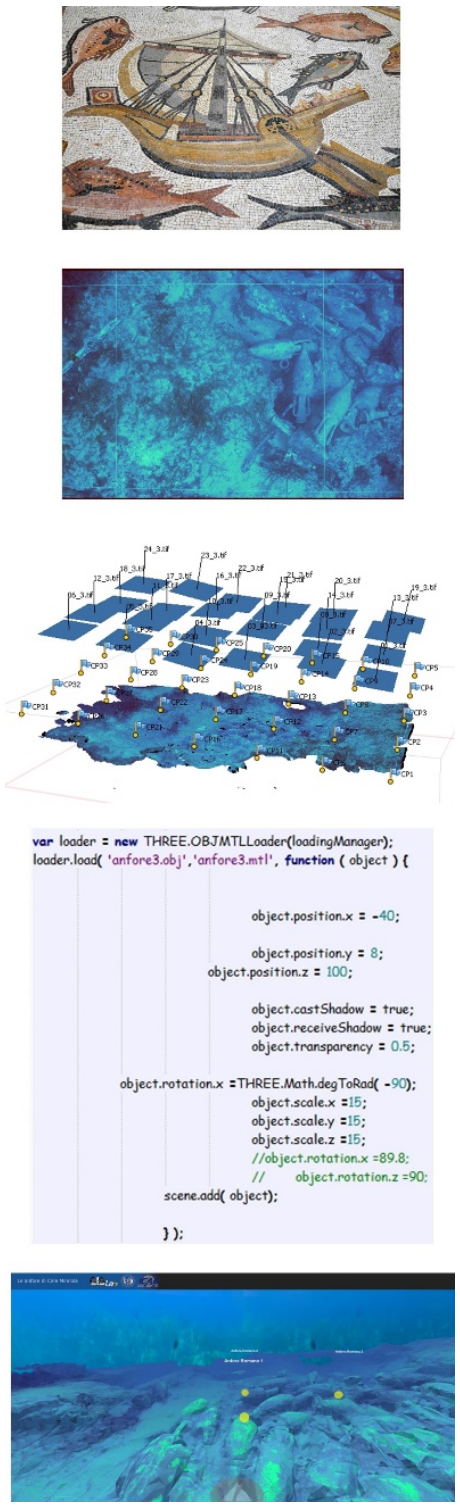

Figure 1: The workflow for the creation of the virtual interactive navigation model.

Firstly, the acquisition of historical background is the base of the research, because it gives the main information necessary for the development of the virtual navigation model and outlines the main archaeological finds to focus. The second phase that consists of survey operations, as affirmed before, was originally intended for a traditional photogrammetric survey. Anyway, the considered dataset contains the necessary information to test this methodology, allowing the digital photogrammetric reconstruction of the considered seabed. The next phase consists of the digital photogrammetric reconstruction of the model, considering a proper network of Ground Control Points (GCP). Once obtained the 3D model, the building of the virtual environment on the web represents the further step of the workflow, where the 3D model should be adapted for the web browsing and every component of the scene should be implemented into the 
webpage using WebGL JavaScript libraries. In the end, the final navigation model should be tested considering the most used browsers for mobile (tablets and smartphones) and PC devices. Every step of the workflow is described below in the following paragraphs.

\subsection{The wreck of Cala Minnola}

The wreck of Cala Minnola is located in front of the island of Levanzo (TP) (Fig. 2), in the archipelago of the Egadi Islands, in Sicily. Discovered around 1970, the site preserves the remains of an ancient Roman ship at a depth of about 30 meters. The wreck, dating back to the $1^{\text {st }}$ century B.C., represents what remains of a Roman ship transporting wine amphorae near Punta Altarella, where the ruins of a factory for the processing of Garum were found.

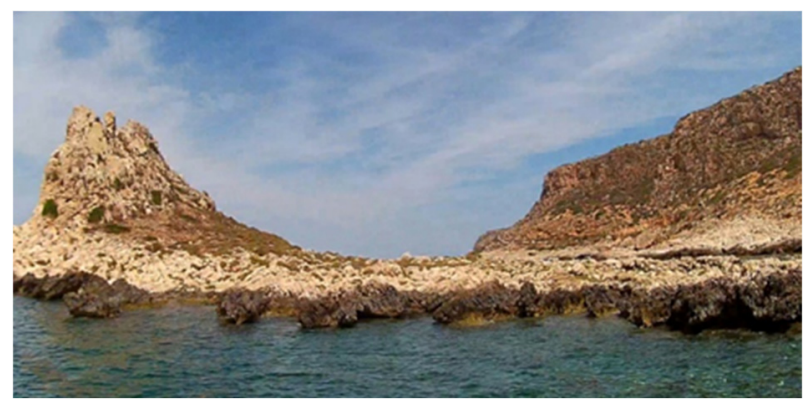

Figure 2: The Levanzo island (TP), Italy.

Further findings have occurred over the years during survey activities. In fact, about 50 amphorae and fragments of them were found, in addition to the wooden remains of the ship. The morphology of the site is quite particular, as it is surrounded by rather high rocks and largely covered with seagrass (Fig. 3).

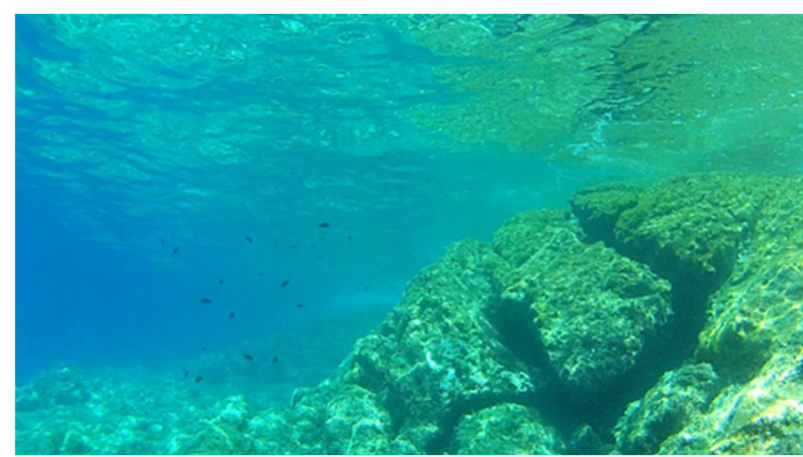

Figure 3: The composition of the seabed in the area of Cala Minnola.

\subsection{The photogrammetric reconstruction}

At the basis of the experimentation, images and measurements provided by a previous survey of the site were used, where the dataset available consisted of only 24 nadiral photos with a resolution of $3671 \times 2481$ pixels, covering a surface of about $96 \mathrm{~m}^{2}$. Each photo covered a specific area (Fig. 4) of the archaeological site of known size $(2 \mathrm{~m} \times 2 \mathrm{~m})$. The photos in question, despite being numerically reduced, were sufficient to reconstruct the archaeological area where the amphorae lie in three dimensions. Furthermore, the availability of a larger survey area would have been superfluous for the purposes of this experimentation, because the same procedure could be carried out with any dataset provided by a correct photogrammetric reconstruction. Otherwise, as explained below, the networking of $3 \mathrm{D}$ environments requires a strong simplification of the original model to optimize web navigation. Consequently, the acquisition of huge datasets of images covering is not ever useful for this aim.

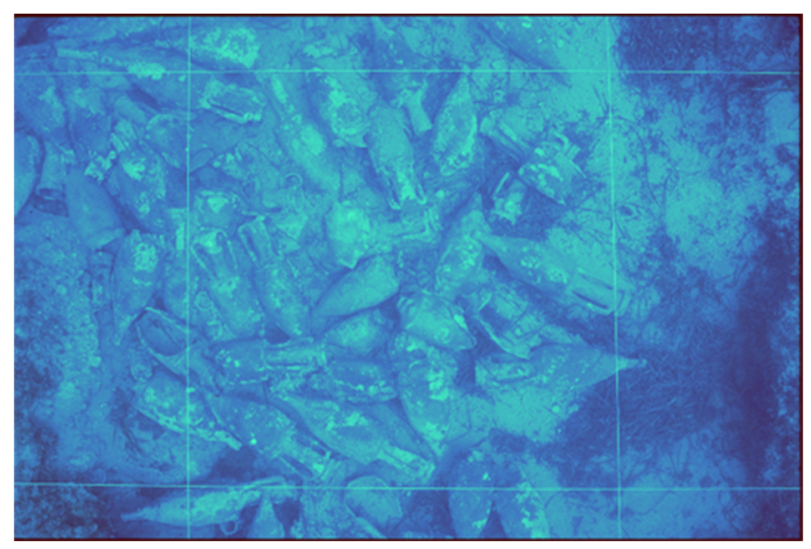

Figure 4: An example of the nadiral photos in the dataset.

The 3D reconstruction was performed using Agisoft Photoscan, a photogrammetric reconstruction software based on SfM algorithms, associating a network of 35 Ground Control Points (GCP) based on a local reference system of known targets (Fig. 5). The local coordinates of every target have been obtained considering the mutual position of the nodes of the $2 \mathrm{~m} \times 2 \mathrm{~m}$ grid used during survey operation. The digital photogrammetric reconstruction achieved a level of accuracy of $0,075 \mathrm{~m}$ (Table 1) of total error (the distance between source and estimated location for marker). This level of accuracy satisfies the requirements for the reconstruction of a $3 \mathrm{D}$ model finalized to the virtual fruition on web and for virtual dissemination of $\mathrm{CH}$, considering the dimensions of the dataset (24 images of 9 MP for $8 \mathrm{~m} \times 12 \mathrm{~m}$ surface) and the underwater conditions on 30 meters deep (problems of refraction and presence of suspensions in water). Furthermore, it's necessary to underline that the dataset wasn't originally obtained for digital photogrammetry reconstruction, but for a traditional photogrammetric survey.

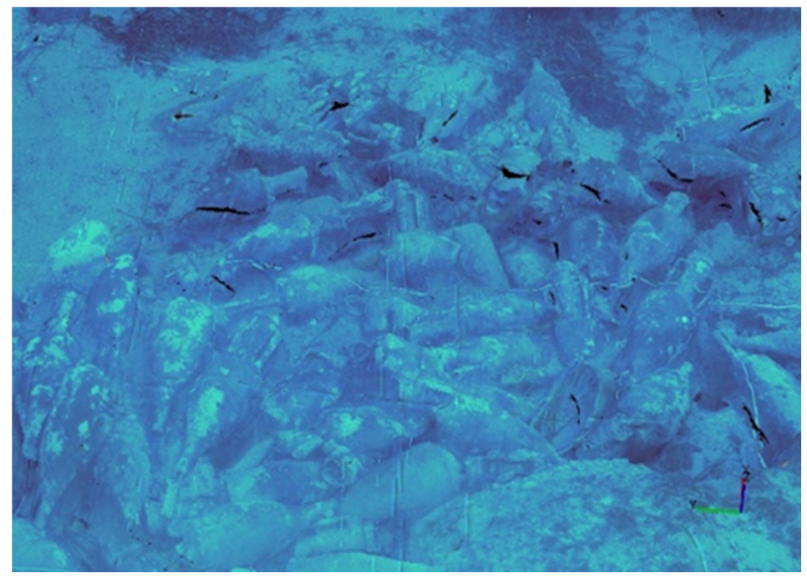

Figure 5: The result of the photogrammetric reconstruction of the site. 
Once generated the 3D reconstruction, the texture associated with the model has been corrected by calibrating the colours appropriately, in order to obtain a more realistic display during the web navigation.

Table 1: The positioning data and the errors found in the photogrammetric reconstruction phase.

\begin{tabular}{|c|c|c|c|c|}
\hline Markers & $X(m)$ & $Y(m)$ & $Z(m)$ & Error $(m)$ \\
\hline CP1 & 0.000 & 0.000 & 0.000 & 0.0761 \\
\hline $\mathrm{CP} 2$ & 2.000 & 0.000 & 0.000 & 0.0721 \\
\hline $\mathrm{CP} 3$ & 4.000 & 0.000 & 0.000 & 0.0726 \\
\hline CP4 & 6.000 & 0.000 & 0.000 & 0.1260 \\
\hline CP5 & 8.000 & 0.000 & 0.000 & 0.0852 \\
\hline CP6 & 0.000 & 2.000 & 0.000 & 0.0857 \\
\hline $\mathrm{CP} 7$ & 2.000 & 2.000 & 0.000 & 0.0565 \\
\hline CP8 & 4.000 & 2.000 & 0.000 & 0.0471 \\
\hline CP9 & 6.000 & 2.000 & 0.000 & 0.1042 \\
\hline CP10 & 8.000 & 2.000 & 0.000 & 0.0574 \\
\hline CP11 & 0.000 & 4.000 & 0.000 & 0.0893 \\
\hline CP12 & 2.000 & 4.000 & 0.000 & 0.0414 \\
\hline CP13 & 4.000 & 4.000 & 0.000 & 0.0445 \\
\hline CP14 & 6.000 & 4.000 & 0.000 & 0.0883 \\
\hline CP15 & 8.000 & 4.000 & 0.000 & 0.0832 \\
\hline CP16 & 0.000 & 6.000 & 0.000 & 0.1077 \\
\hline CP17 & 2.000 & 6.000 & 0.000 & 0.0248 \\
\hline CP18 & 4.000 & 6.000 & 0.000 & 0.0369 \\
\hline CP19 & 6.000 & 6.000 & 0.000 & 0.0843 \\
\hline CP20 & 8.000 & 6.000 & 0.000 & 0.1350 \\
\hline CP21 & 0.000 & 8.000 & 0.000 & 0.1181 \\
\hline CP22 & 2.000 & 8.000 & 0.000 & 0.0248 \\
\hline CP23 & 4.000 & 8.000 & 0.000 & 0.0415 \\
\hline CP24 & 6.000 & 8.000 & 0.000 & 0.0751 \\
\hline CP25 & 8.000 & 8.000 & 0.000 & 0.0842 \\
\hline CP26 & 0.000 & 10.000 & 0.000 & 0.1245 \\
\hline CP27 & 2.000 & 10.000 & 0.000 & 0.0460 \\
\hline CP28 & 4.000 & 10.000 & 0.000 & 0.0366 \\
\hline CP29 & 6.000 & 10.000 & 0.000 & 0.0666 \\
\hline CP30 & 8.000 & 10.000 & 0.000 & 0.0552 \\
\hline CP31 & 0.000 & 12.000 & 0.000 & 0.1001 \\
\hline CP32 & 2.000 & 12.000 & 0.000 & 0.0280 \\
\hline CP33 & 4.000 & 12.000 & 0.000 & 0.0642 \\
\hline CP34 & 6.000 & 12.000 & 0.000 & 0.0841 \\
\hline CP35 & 8.000 & 12.000 & 0.000 & 0.0461 \\
\hline Total Error & & & & 0.0758 \\
\hline
\end{tabular}

\subsection{The web visualization using WebGL libraries}

The 3D model, generated from the photogrammetric reconstruction, was properly simplified and adapted to web browsing, for the construction of the interactive navigation model. Virtual web navigation, in fact, requires the use of simplified 3D models, with the dimension not exceeding 10-15 MB, as seen in the data summary (Tables 2 and 3 ). More complex models, with a larger number of polygons, are not useful for web navigation, as they would crash the webpage. In light of this, the absence of the 3D model of the surrounding environment did not constitute a serious loss for navigation purposes, in fact, it would have been omitted to optimize performance during online viewing.

Table 2: Survey and Digital Photogrammetric reconstruction data. Summary of the process.

\begin{tabular}{c|c} 
Setting & Value \\
\hline Number of images & 24 \\
Image resolution & $3671 \times 2481$ pix \\
Surveyed area dimension & $8 \times 12 \mathrm{~m}$ \\
Number of GCP & 35 \\
$\begin{array}{c}\text { Level of Accuracy of } \\
\text { photogrammetric } \\
\text { reconstruction }\end{array}$ & $0-0.13 \mathrm{~m}$
\end{tabular}

Table 3: WebGL environment data. Summary of the process.

\begin{tabular}{c|c} 
Setting & Value \\
\hline Dimensions of the 3D mesh & $11.3 \mathrm{MB}$ \\
Texture resolution & $8192 \times 8192 \mathrm{pix}$ \\
$\begin{array}{c}\text { Background texture } \\
\text { resolution }\end{array}$ & $2672 \times 900$ pix
\end{tabular}

The surrounding environment, on the other hand, was reproduced by inserting a $360^{\circ}$ image of the underwater environment into the inner surface of a sphere. The spherical geometry contains the entire interior of the reconstructed model of the amphorae, so as to become the background displayed during web navigation (Fig. 6).

This solution offers a realistic visualization on the web, and, at the same time, doesn't oversize the dimension of the $3 \mathrm{D}$ model during the web-browsing with further geometric information of surrounding environments.

The spherical geometry and the reconstructed model generated inside Agisoft Photoscan software, were finally uploaded to the server in .obj format, and loaded into the main webpage, using the Javascript language and loading external WebGL libraries, necessary to visualize the environment online. Once the elements, to be displayed within the virtual environment, have been defined, it was necessary to study a simple and intuitive navigation system, for both desktop PCs and mobile devices (Fig. 7). Using the JavaScript WebGL libraries based on Three.js, a first-person navigation system was developed, which allowed the viewer to move freely along a horizontal plane, with the possibility of interacting through information popups along the way. The viewer is anchored to a sphere that can be pushed by the user by pressing the forward button. In this way, the sphere undergoes a force that moves the viewer in the direction 
chosen by the user along with an invisible horizontal plan with a proper coefficient of friction. Finally, effects were also included in the rendering phase, simulating the underwater environment to guarantee more realistic navigation.

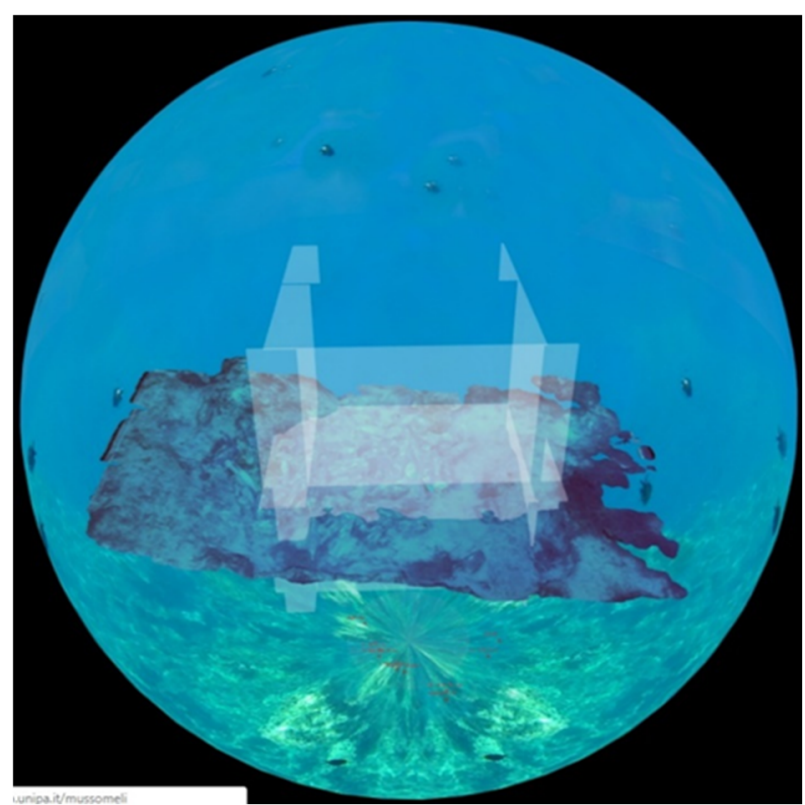

Figure 6: The architecture of the 3D environment. It's possible to notice the sphere that contains the entire environment and the transparent boundaries that limit navigation.

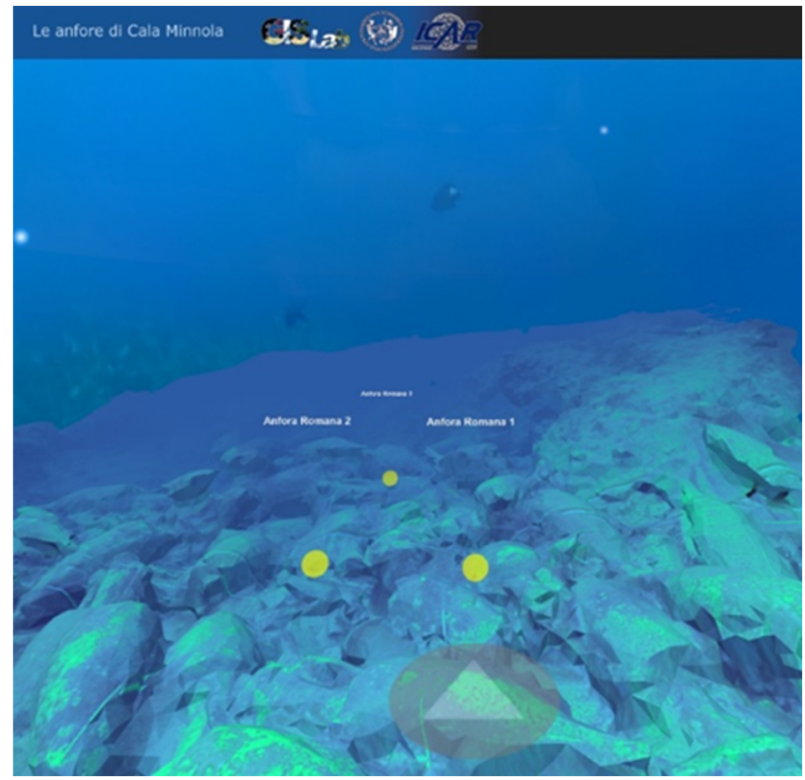

Figure 7: The online visualization of the interactive first-person navigation and the system of yellow popups along the path.

The structure of the $3 \mathrm{D}$ visualization and the navigation system have been implemented directly in the .html page, within links to external JavaScript libraries and JavaScript strings inside the same page. The system of popups placed along the 3D environments allowed users to click and open external html pages with further information about the site (Fig. 8).

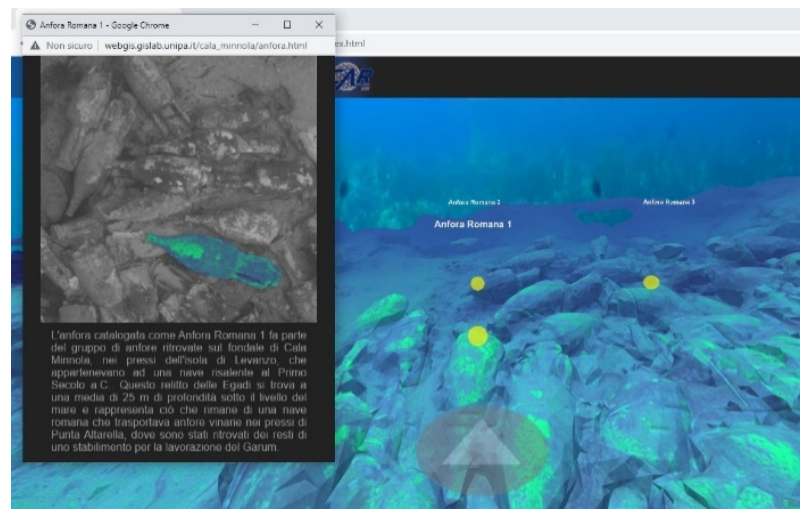

Figure 8: An example of the popups implemented in the web navigation model.

The web navigation model is freely online available, for both desktop PCs and mobile devices, on the GISLab Website using the following Link: http://webgis.gislab.unipa.it/cala_minnola/index.html.

\section{Conclusions and open scenarios}

The growing diffusion of devices, that allow access to information on the web from anywhere and at any time, has underlined the importance of sharing 3D models of cultural heritage and archaeological sites online, directly navigable, without the need to install any application. In this way, it is possible not only to facilitate disabled people to visit virtually an archaeological asset, but, in general, to offer anyone the opportunity to visit places that are otherwise difficult to access, enhancing their visibility. Although there are, still, some limitations mainly related to the size of the 3D models to be displayed, as highlighted by the case study, the use of the WebGL libraries constitutes a valid option for the online use of Cultural Heritage, as they allow you to discover virtual environments and 3D models directly through webbrowser. Obviously, virtual navigation cannot replace the real visit to the place of interest, but it certainly constitutes a powerful means of spreading knowledge and therefore arousing interest and curiosity. Therefore, online use is not, in any case, to be understood as a substitute factor for the real visit, but as an element of enhancement, which can act as a catalyst for the real use of the asset. In the future, the development of increasingly high-performance internet connections will broaden the possibilities already offered by the world of VR, allowing the insertion of increasingly complex and information-rich navigable environments.

\section{References}

Ballarin, M., Balletti, C., \& Vernier, P. (2018). Replicas In Cultural Heritage: 3d Printing And The Museum Experience. The International Archives of the Photogrammetry, Remote Sensing and Spatial Information Sciences, XLII-2, 55-62. https://doi.org/10.5194/isprs-archives-XLII-2-55-2018

Balletti, C., Beltrame, C., Costa, E., Guerra, F., \& Vernier, P. (2015). Underwater Photogrammetry And 3d Reconstruction Of Marble Cargos Shipwreck. The International Archives of the Photogrammetry, Remote Sensing and Spatial 
Information Sciences, XL-5/W5, 7-13. https://doi.org/10.5194/isprsarchives-XL-5-W5-7-2015

Banfi, F. (2020). HBIM, 3D drawing and virtual reality for archaeological sites and ancient ruins. Virtual Archaeology Review, 11(23), pp. 16-33. https://doi.org/10.4995/var.2020.12416

Barrile, V., Fotia, A., Bilotta, G., \& De Carlo, D. (2019). Integration of geomatics methodologies and creation of a cultural heritage app using augmented reality. Virtual Archaeology Review, 10(20), pp. 40-51. https://doi.org/10.4995/var.2019.10361

Bass, G. (1966). Archaeology under water. Bristol: Thames and Hudson.

Becattini, F., Ferracani, A., Landucci, L., Pezzatini, D., Uricchio, T., \& Del Bimbo, A. (2016). Imaging Novecento. A Mobile App for Automatic Recognition of Artworks and Transfer of Artistic Styles. loannides M. et al. (eds) Digital Heritage. Progress in Cultural Heritage: Documentation, Preservation, and Protection. EuroMed 2016. Lecture Notes in Computer Science, 10058. Springer, Cham. https://doi.org/10.1007/978-3-319-48496-9_62

Bekele, M. K., Pierdicca, R., Frontoni, E., Malinverni, E. S., \& Gain, J. (2018). A Survey of Augmented, Virtual, and Mixed Reality for Cultural Heritage. Journal on Computing and Cultural Heritage, 11(2). https://doi.org/10.1145/3145534

Brovelli, M. A., Hogan, P., Minghini, M., \& Zamboni, G. (2013). The power of Virtual Globes for valorising cultural heritage and enabling sustainable tourism: NASA World Wind applications. International Archives of the Photogrammetry, Remote Sensing and Spatial Information Sciences, XL-4/W2, 115-120. https://doi.org/10.5194/isprsarchives-XL-4W2-115-2013

Bruno, F., Bruno, S., De Sensi, G., Luchi, M.L., Mancuso, S., \& Muzzupappa, M. (2010). From 3D reconstruction to virtual reality: A complete methodology for digital archaeological exhibition. Journal of Cultural Heritage, 11, 42-49. https://doi.org/10.1016/j.culher.2009.02.006

Bruno, F., Lagudi, A., Barbieri, L., Muzzupappa, M., Mangeruga, M., Pupo, F., Cozza, M., Cozza, C., Ritacco, G., Peluso, R., \& Tusa, S. (2017). Virtual Diving In The Underwater Archaeological Site Of Cala Minnola. The International Archives of the Photogrammetry, Remote Sensing and Spatial Information Sciences, XLII-2/W3, $121-126$. https://doi.org/10.5194/isprs-archives-XLII-2-W3-121-2017

Campanaro, D. M., Landeschi, G., Dell'Unto, N., \& Touati, A. M. L. (2016). 3D GIS for cultural heritage restoration: A 'white box' workflow. Journal of Cultural Heritage, 18, pp. 321-332. https://doi.org/10.1016/j.culher.2015.09.006

Canciani, M., Gambogi, P., Romano, F., Cannata, G., \& Drap, P. (2003). Low cost digital photogrammetry for underwater archaeological site survey and artifact isertion. The case study of the Dolia wreck in Secche della Meloria-LivornoItalia. ISPRS Workshop Vision Tecniques for digital architectural and archaeological archives, Jul 2003, Portugal. 〈halshs-00271413〉

Carrozzino, M., \& Bergamasco, M. (2010). Beyond virtual museums: Experiencing immersive virtual reality in real museums. Journal of Cultural Heritage, 11(4), 452-458. https://doi.org/10.1016/j.culher.2010.04.001

Dominici, D., Alicandro, M. \& Massimi V. (2017). UAV photogrammetry in the post-earthquake scenario: case studies in L'Aquila. Geomatics, Natural Hazards and Risk, 8(1), 87-103. https://doi.org/10.1080/19475705.2016.1176605

Farella, E., Brunelli, D., Benini, L., Ricco B.\& Bonfigli, M. E. (2005). Pervasive computing for interactive virtual heritage. IEEE MultiMedia, 12(3), pp. 46-58, July-Sept. https://doi.org/10.1109/MMUL.2005.54

Fernández-Palacios, B. J., Morabito, D., Remondino, F. (2017). Access to complex reality-based 3D models using virtual reality solutions. Journal of Cultural Heritage, 23, 2017, pp. 40-48. https://doi.org/10.1016/j.culher.2016.09.003

Grün, A., Remondino, F., \& Zhang, L. (2004). Photogrammetric reconstruction of the great Buddha of Bamiyan, Afghanistan. The Photogrammetric Record, 19(107), 177-199. https://doi.org/10.1111/j.0031-868X.2004.00278.x

Ioannides, M., Davies, R., Chatzigrigoriou, P., Papageorgiou, E., Leventis, G., Nikolakopoulou, V., \& Athanasiou, V. (2017). 3D Digital Libraries and Their Contribution in the Documentation of the Past. Ioannides M., Magnenat-Thalmann N., Papagiannakis G. (Eds) Mixed Reality and Gamification for Cultural Heritage. Springer, Cham. https://doi.org/10.1007/978-3-319-49607-8_6

Kersten, T. P. (2018). 3D Models and Virtual Tours for a Museum Exhibition of Vietnamese Cultural Heritage Exhibits and Sites. Ioannides M. et al. (Eds) Digital Heritage. Progress in Cultural Heritage: Documentation, Preservation, and Protection. EuroMed 2018. Lecture Notes in Computer Science, 11196. Springer, Cham. https://doi.org/10.1007/9783-030-01762-0_46

Lepouras, G., \& Vassilakis, C. (2005). Virtual museums for all: employing game technology for edutainment. Virtual Reality 8(2), 96-106, ISSN 1359-4338

Levoy, M., Pulli, K., Curless, B., Rusinkiewicz, S., Koller, D., Pereira, L., Ginzton, M., Anderson, S., Davis, J., Ginsberg, J., Shade, J., \& Fulk, D. (2000). The digital Michelangelo project: 3D scanning of large statues. Proceedings of the 27th annual conference on Computer graphics and interactive techniques, pp. 131-144. ACM Press/Addison-Wesley Publishing Co. https://doi.org/10.1145/344779.344849

Liarokapis, F., Kouřil, P., Agrafiotis, P., Demesticha, S., Chmelík, J., \& Skarlatos, D. (2017). 3d Modelling And Mapping For Virtual Exploration Of Underwater Archaeology Assets. The International Archives of the Photogrammetry, 
Remote Sensing and Spatial Information Sciences, XLII-2/W3, 425-431. https://doi.org/10.5194/isprs-archives-XLII2-W3-425-2017

Magnenat-Thalmann, N., \& Papagiannakis, G. (2005). Virtual worlds and augmented reality in cultural heritage applications. Recording, modeling and visualization of cultural heritage, 419-430.

Masiero, A., Chiabrando, F., Lingua, A. M., Marino, B. G., Fissore, F., Guarnieri, A., \& Vettore, A. (2019). 3d Modeling Of Girifalco Fortress. The International Archives of the Photogrammetry, Remote Sensing and Spatial Information Sciences, XLII-2/W9, 473-478. https://doi.org/10.5194/isprs-archives-XLII-2-W9-473-2019

Meschini, A. (2011). Tecnologie digitali e comunicazione dei beni culturali. Stato dell'arte e prospettive di sviluppo. Disegnarecon, 4(8), 14-24. https://doi.org/10.6092/issn.1828-5961/2565

Menna, F., Agrafiotis, P., \& Georgopoulos, A. (2018). State of the art and applications in archaeological underwater 3D recording and mapping. Journal of Cultural Heritage, 33, 231-248. https://doi.org/10.1016/j.culher.2018.02.017

Mortara, M., Catalano, C. E., Bellotti, F., Fiucci, G., Houry-Panchetti, M., \& Petridis, P. (2014). Learning cultural heritage by serious games. Journal of Cultural Heritage, 15(3), 2014, pp. 318-325, https://doi.org/10.1016/j.culher.2013.04.004

Pacheco-Ruiz, R., Adams, J., \& Pedrotti, F. (2018). 4D modelling of low visibility Underwater Archaeological excavations using multi-source photogrammetry in the Bulgarian Black Sea. Journal of Archaeological Science, 100, $2018, \mathrm{pp}$. 120-129, ISSN 0305-4403. https://doi.org/10.1016/j.jas.2018.10.005

Scianna, A., Gaglio, G. F., \& La Guardia, M. (2020). Digital Photogrammetry, Tls Survey And 3d Modelling For Vr And Ar Applications In Ch. The International Archives of the Photogrammetry, Remote Sensing and Spatial Information Sciences, XLIII-B2-2020, 901-909. https://doi.org/10.5194/isprs-archives-XLIII-B2-2020-901-2020

Scianna, A., La Guardia, M. (2019). Survey and Photogrammetric Restitution of Monumental Complexes: Issues and Solutions-The Case of the Manfredonic Castle of Mussomeli. Heritage 2019, 2, 774-786. https://doi.org/10.3390/heritage2010050

Scianna, A., \& La Guardia, M. (2018). 3D Virtual CH Interactive Information Systems for a smart web browsing experience for desktop PCs and mobile devices. The International Archives of the Photogrammetry, Remote Sensing and Spatial Information Sciences, XLII-2, 1053-1059. https://doi.org/10.5194/isprs-archives-XLII-2-1053-2018.

Scianna A., La Guardia M., \& Scaduto M.L. (2016). Definition of a Workflow for Web Browsing of 3D Models in Archaeology. loannides M. et al. (eds) Digital Heritage. Progress in Cultural Heritage: Documentation, Preservation, and Protection. EuroMed 2016. Lecture Notes in Computer Science, vol 10059. Springer, Cham. https://doi.org/10.1007/978-3-319-48974-2_6

Skarlatos D., \& Agrafiotis P. (2020). Image-Based Underwater 3D Reconstruction for Cultural Heritage: From Image Collection to 3D. Critical Steps and Considerations. Liarokapis F., Voulodimos A., Doulamis N., Doulamis A. (eds) Visual Computing for Cultural Heritage. Springer Series on Cultural Computing. Springer, Cham. https://doi.org/10.1007/978-3-030-37191-3_8

Skarlatos, D., Menna, F., Nocerino, E., \& Agrafiotis, P. (2019). Precision Potential Of Underwater Networks For Archaeological Excavation Through Trilateration And Photogrammetry. The International Archives of the Photogrammetry, Remote Sensing and Spatial Information Sciences, XLII-2/W10, 175-180, https://doi.org/10.5194/isprs-archives-XLII-2-W10-175-2019

Vlachos, M., Berger, L., Mathelier, R., Agrafiotis, P., \& Skarlatos, D. (2019). Software Comparison For Underwater Archaeological Photogrammetric Applications. The International Archives of the Photogrammetry, Remote Sensing and Spatial Information Sciences, XLII-2/W15, 1195-1201. https://doi.org/10.5194/isprs-archives-XLII-2-W15-11952019

Walczak, K., Cellary, W., \& White, M. (2006). Virtual museum exbibitions. Computer, 39(3), 93-95. https://doi.org/10.1109/MC.2006.108

White, M., Mourkoussis, N., Darcy, J., Petridis, P., Liarokapis, F., Lister, P., Walczak, K., Wojciechowski, R., Cellary, W., Chmielewski, J., Stawniak, M., Wiza, W., Patel, M., Stevenson, J., Manley, J., Giorgini, F., Sayd, P. Gaspard, F. (2004). ARCO_An Architecture for Digitization, Management and Presentation of Virtual Exhibitions. Proceedings Computer Graphics International, 622-625. https://doi.org/10.1109/CGI.2004.1309277

Yamafune, K., Torres, R., \& Castro, F. (2017). Multi-Image Photogrammetry to Record and Reconstruct Underwater Shipwreck Sites. Journal of Archaeological Method and Theory, 24(3), 703-725. https://doi.org/10.1007/s10816-0169283-1 